\title{
Aniela Meyer Ginsberg e os estudos de raça/etnia e intercultura no Brasil ${ }^{1}$
}

\author{
Renata Rocha Tsuji da Cunha *, Alessandro de Oliveira dos Santos \\ Instituto de Psicologia da Universidade de São Paulo, São Paulo, SP, Brasil
}

Resumo: Este ensaio delineia as contribuições de Aniela Meyer Ginsberg (1902-1986) para o estudo das relações étnico-raciais e interculturais no Brasil. Sua produção sobre estes temas - entre artigos, capítulos de livros e resumos de congressos - foi nosso objeto central de interesse. Influenciada pela agenda antirracista do pós-guerra, os processos inter e intraculturais, as relações étnico-raciais e as migrações estavam no centro de suas investigações. Aniela é uma personagem importante da história do pensamento psicológico brasileiro, seus estudos sobre raça/ etnia no Brasil configuram-se como estudos intraculturais da sociedade nacional e de suas amplas diversidades. A autora procurou desconstruir a visão determinista biológica das raças/etnias e mostrar que é na interação dos indivíduos com a sociedade que as diferenças podem transformar-se em desigualdades.

Palavras-chave: Aniela Meyer Ginsberg, raça e etnia, intercultura, Psicologia Social, História da Psicologia - Brasil.

\section{Introdução}

No final da década de 1940, o horror da Segunda Guerra e do Holocausto e a busca pela compreensão desses fenômenos de intolerância racial e genocídio intensificaram os estudos sobre relações étnico-raciais e interculturais. Pesquisas sobre estereótipos, atitudes e caráter nacional entraram, então, na agenda comum das ciências humanas do pós-guerra (Maio, 1999). O início da Guerra Fria e dos processos de descolonização de países africanos e asiáticos, nas décadas seguintes, e a persistência do apartheid racial - principalmente nos Estados Unidos e na África do Sul - mantiveram a atualidade da temática racial.

Dessa forma, após as tragédias da Segunda Guerra, assistiu-se a um esforço dos cientistas, tanto em psicologia como nas demais ciências humanas, para extinguir a ideia de raça, desautorizando seu uso como categoria científica. Buscava-se, então, explicar as diferentes características físicas, psicológicas e intelectuais da população por meio de fatores ambientais (condições sociais, econômicas e educacionais), e não mais pelo pertencimento a diferentes grupos raciais, em uma tentativa de desconstruir a ideia de que determinantes genéticos pudessem causar essas diferenças.

A raça, porém, permanece como um constructo sociológico, efeito de discursos e que só faz sentido em um determinado contexto histórico, articulado a uma teoria, uma vez que não é possível definir geneticamente

1 Este ensaio é derivado de pesquisa de Iniciação Científica, orientada pelo Prof. Dr. Alessandro Oliveira dos Santos no Instituto de Psicologia da Universidade de São Paulo. Apoio financeiro da RUSP.

Agradecimentos: À Dra. Mônica Leopardi Bosco Azevedo, pela colabo-

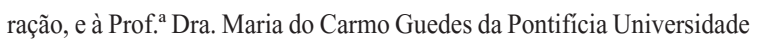
Católica de São Paulo, pelas orientações e pelo apoio.

* Autor correspondente: renatartc@usp.br diferentes raças humanas. Trata-se, portanto, de uma construção social que remete à origem de um grupo com base na transmissão de traços fisionômicos, transpostos para qualidades morais e intelectuais. Também é um discurso sobre o lugar de onde se veio e, neste caso, remete à etnia - conjunto de indivíduos que histórica ou mitologicamente têm um mesmo ancestral, uma língua em comum, mesma religião e cultura, e compartilham o mesmo território. A cor, por sua vez, categoria mais habitual e naturalizada de todas, é orientada pela própria ideia de raça, ou seja, por um discurso classificatório sobre qualidades, características e essências transmitidas pelo sangue, que também remontam a um ancestral comum. (Guimarães, 2003).

Destarte, utilizar apenas o termo etnia para designar a população negra brasileira - e de descendentes de imigrantes europeus e asiáticos - parece insuficiente, visto que não existe um mesmo ancestral comum, seus ancestrais vieram de vários territórios e se misturaram no país, configurando um verdadeiro "caldeirão étnico". Por outro lado, é o termo raça que melhor expressa as diferenças e desigualdades no país, evidenciando diferentes experiências de nascer, viver e morrer, conforme o pertencimento racial da população. Por isso, neste artigo optou-se por utilizar, sempre que possível, os dois termos juntos: étnico-racial.

No Brasil, desde o início dos anos 1930, o governo populista de Vargas pretendia modernizar o país, formar uma nova sociedade urbana e, mais especificamente, uma nova mão-de-obra qualificada e especializada para suprir a indústria nacional. Os métodos e técnicas psicológicas auxiliaram de maneira bastante significativa no adestramento do trabalhador ao emprego, colaborando para tornar reais as pretensões modernistas da sociedade brasileira (Martins et al., 2011).

Nesse período, o campo dos saberes psicológicos se expande com a introdução dos primeiros cursos de Psicologia no ensino superior brasileiro, atendendo à 
crescente demanda por métodos e técnicas qualificadas na organização do trabalho e no ajustamento de crianças e adolescentes na educação e nas clínicas infantis. "A meta nacionalista daquele momento era possibilitar a construção de um homem novo para um país novo, e a fundamentação dessa meta era buscada no positivismo e no tecnicismo, com a Psicologia funcionando como apoio" (Baptista, 2010, p. 172).

As mudanças econômicas, sociais e políticas decorrentes da Revolução de 1930 no Brasil também colocaram em foco os esforços para a constituição de uma identidade nacional. Para Arthur Ramos (1948) o tema das relações étnico-raciais oferecia um ponto de vista privilegiado para a percepção e análise dos desafios de transição do tradicional para o moderno e a superação das diferenças sociais, étnico-raciais e regionais, na busca de uma identidade nacional definitiva. Para ele, seria conveniente (e necessário) estudar o passado escravocrata e suas consequências para as relações étnico-raciais no Brasil, principalmente "a influência psico-sociológica dos grupos dominantes, não negros" (Ramos, 1948, p. 219), os estereótipos e as atitudes.

A constituição de uma identidade nacional dependia da integração de negros, indígenas e imigrantes ao mundo moderno e à sociedade brasileira. Assim, entre os anos 1920 e 1950, a visão pessimista sobre a contribuição das diferentes raças/etnias na formação da sociedade brasileira deu lugar à crença controvertida numa democracia racial, símbolo de tolerância e convivência harmoniosa, na visão de brasileiros e estrangeiros.

No início da década de 1950, a Organização das Nações Unidas para a Educação, Ciência e Cultura (Unesco) patrocinou uma série de estudos sobre as relações étnico-raciais no Brasil. As investigações foram realizadas em Estados de regiões economicamente tradicionais, como Pernambuco e Bahia, e de regiões mais modernas, como o Sudeste. Os estudos realizados em São Paulo foram coordenados por Roger Bastide e Florestan Fernandes e seus resultados, publicados no livro Relações Raciais entre Negros e Brancos em São Paulo (Bastide \& Fernandes, 1955). A psicologia social foi chamada a dar sua contribuição ao Projeto Unesco, com Aniela Ginsberg (como veremos mais adiante) e Virgínia Leone Bicudo, para o entendimento da então considerada "experiência bem sucedida" de acomodação das diferenças étnico-raciais no Brasil, país considerado um contraexemplo em matéria de racismo.

O Projeto Unesco, como ficou conhecido, gerou um amplo e diversificado quadro das relações étnico-raciais brasileiras e contribuiu para o surgimento de novas leituras sobre a sociedade nacional no contexto do processo de modernização (Maio, 1999). Em São Paulo, que há pouco tempo havia se tornado o maior centro industrial da América Latina, coexistiam, segundo Bastide e Fernandes (1955), "sobrevivências da sociedade escravagista e inovações da sociedade capitalista" (p. 11), e o preconceito de cor, "cuja função era justificar o trabalho servil do africano, vai servir agora para justificar uma sociedade de classes, mas nem por isso vão variar os estereótipos antigos; mudarão apenas de finalidade".

Para o Projeto Unesco, Virgínia Leone Bicudo realizou o trabalho Atitudes dos Alunos dos Grupos Escolares em Relação com a Cor dos seus Alunos, analisando atitudes de intimidade, aproximação e/ou rejeição dos estudantes devido à cor da pele, e a influência familiar na formação dessas preferências e preconceitos. Alguns anos antes, em 1945, Virgínia concluíra sua dissertação de mestrado, a primeira sobre a "questão racial" a ser defendida em uma instituição brasileira de ensino superior: Estudo de Atitudes Raciais de Pretos e Mulatos em São Paulo. Nesse estudo (Bicudo, 1945), ela articulou análise sociológica (estrutura de classes, mobilidade social, preconceitos) com psicologia social (atitudes sociais). A partir de entrevistas com pais de alunos de escolas públicas residentes em quatro bairros populares e um de classe média de São Paulo e com ex-militantes da Frente Negra Brasileira (FNB), organização negra anti-racista criada em 1931, a autora concluiu que existe o preconceito de cor, e que a cor se constituía como uma barreira à ascensão social de homens e mulheres pretos e "mulatos". Apesar dos esforços pela conquista de novo status social, por meio da educação e formação profissional, a eliminação "das distâncias sociais na linha de cor" não ocorria, devido à persistência do preconceito de cor (Bicudo, 1945, p. 65).

Virgínia apresentou uma reflexão inovadora ao considerar cor e raça/etnia como variáveis importantes na produção de diferenças e desigualdades na sociedade brasileira, em um momento em que eram realizadas as pesquisas iniciais sobre atitudes raciais (preconceitos e estereótipos) nos Estados Unidos, buscando fazer frente ao darwinismo social e ao determinismo biológico das raças (Maio, 2010).

Nessa mesma direção, na metade da década de 1950, o psicólogo social Dante Moreira Leite defende sua Tese de Doutorado na Faculdade de Filosofia, Letras e Ciências Humanas da Universidade de São Paulo sobre o caráter nacional brasileiro: a atribuição ao povo brasileiro de características psicológicas descritas como típicas (Leite, 1954). Dante procurou mostrar a inconsistência do conceito de caráter nacional, por ser um fenômeno social marcado por estereótipos e preconceitos - percepções deformadas da realidade social e carregadas de valores subjetivos e culturais - cuja principal função era justificar a continuidade de formas de dominação política, social e étnico-racial. No livro Psicologia Diferencial, de 1966, o autor comenta que:

Quando dois grupos raciais vivem na mesma sociedade, quase nunca eles têm os mesmos direitos e as mesmas oportunidades ... o grupo dominante tende [então] a atribuir tais características indesejáveis ao grupo dominado e a justificar, através delas, a situação de inferioridade em que coloca este último. (Leite, 1966, pp. 112-113)

Nessa obra, Dante denunciou a forte conotação racista do caráter nacional brasileiro, uma vez que as 
características pessimistas nele estabelecidas se destinavam às classes pobres constituídas, em grande maioria, por mulheres e homens negros descendentes de escravos. Além disso, defendeu que as características psicológicas não poderiam ser compreendidas como explicação de condições sociais, uma vez que estas é que determinam as características psicológicas, que só depois irão interagir com e sobre o meio (Bosi, 2000; Graciano, 1976; Paiva, 2000).

O período de 1930 a 1960 é caracterizado pelo intenso debate sobre a construção sociocultural das diferenças na psicologia brasileira. Trata-se de um período de crítica e de desconstrução do determinismo biológico das raças, iniciando um processo de ruptura e configuração de novos saberes em psicologia sobre as relações étnico-raciais no Brasil (Santos, Schucman, \& Martins, 2012).

Aniela Meyer Ginsberg (1902-1986) é uma das principais autoras de psicologia desse período dedicada ao tema das diferenças, junto a Dante Moreira Leite ${ }^{2}$ e Virgínia Leone Bicudo. De 1947 a 1978, ela publica diversos trabalhos sobre intercultura e raça/etnia no Brasil, entre artigos, capítulos de livros e resumos de congressos. Neste artigo, alinhavamos suas principais contribuições para os estudos em psicologia na área de intercultura e raça/etnia no Brasil. A produção de Aniela foi o objeto central de interesse, paralelamente ao levantamento bibliográfico e documental referente aos principais objetivos de investigação abordados em seus escritos e ao contexto sócio-histórico de sua produção.

Aniela Ginsberg lecionou na Escola Livre de Sociologia e Política de São Paulo, na Universidade da Bahia e na Pontifícia Universidade Católica de São Paulo, e participou da criação e do desenvolvimento de várias instituições voltadas para a pesquisa e o ensino em psicologia, como o IDORT-SP (Instituto de Organização Racional do Trabalho), o ISOP-RJ (Instituto de Seleção e Orientação Profissional) e o Instituto de Pedagogia e Psicologia da PUC-SP (IPPUCSP). Filha de poloneses, Aniela transcorreu sua infância durante o período da Primeira Guerra. Formou-se na Universidade de Varsóvia, obtendo o título de Doctor Philosophie (doutoramento) em 1933. Em 1936, chegou ao Brasil e aqui encontrou a diversidade étnico-racial da população em ampla convivência dentro de uma estrutura de desigualdades e discriminação. Assim, o Brasil configurou-se para ela como uma sociedade intrigante e, ao mesmo tempo, um "laboratório social perfeito" para suas pesquisas interculturais (Ginsberg, 1978a, p. 7).

\section{Pesquisa bibliográfica e documental da produção de Aniela Ginsberg sobre inter- cultura e raça/etnia}

A pesquisa bibliográfica e documental da produção de Aniela foi realizada nos Centros de Documentação

2 Aniela Ginsberg e Dante Moreira Leite foram responsáveis pelos primeiros cursos de Psicologia Diferencial no Brasil. Em 1953, ela publica um capítulo com esse título no livro Psicologia Moderna, de Otto Klineberg (1953). Dante publica seu livro Psicologia Diferencial em 1966.
(CEDOCs) das bibliotecas: Dante Moreira Leite do Instituto de Psicologia da Universidade de São Paulo e Nadir Kfouri da Pontifícia Universidade Católica de São Paulo; e no acervo da Fundação Aniela e Tadeuz Ginsberg (FATG), em São Paulo.

Ao todo, foram encontradas cerca de quarenta produções da autora na área de raça/etnia e intercultura, entre artigos, capítulos de livros e resumos de congressos. Aniela derivava vários trabalhos de uma mesma pesquisa (artigos publicados em português, inglês e francês, e resumos apresentados em diferentes congressos). Por isso, foram selecionadas para uma análise mais detalhada 12 produções - 8 artigos científicos e 4 capítulos de livro - que, em seu conjunto, abrangem o campo de investigações e os principais resultados das pesquisas realizadas pela autora, sendo a primeira de 1947 e a última de 1978. As 12 produções foram lidas integralmente, registradas e organizadas em quadros demonstrativos, contendo: título e ano, fonte (local onde foi publicado), objetivo(s), método(s) utilizado(s), população sob estudo e forma de classificação étnico-racial dos sujeitos pesquisados. Os Quadros 1 e 2, em anexo, apresentam a organização da produção de Aniela.

Após a leitura e a organização da produção em quadros demonstrativos, iniciou-se o trabalho de análise de conteúdo e a elaboração de resenhas críticas. A análise de conteúdo consistiu em um processo de codificação e interpretação das informações contidas no material bibliográfico e documental, buscando-se a caracterização dos fenômenos pesquisados, as bases teóricas, os conceitos e, principalmente, os caminhos metodológicos utilizados pela pesquisadora.

A elaboração de resenhas críticas focalizou os principais conteúdos da produção de Aniela e suas contribuições para os estudos na área de intercultura e raça/etnia, permitindo reconstituir um momento importante da história do pensamento psicológico brasileiro sobre as relações étnico-raciais.

\section{Os estudos de Aniela Ginsberg na área de intercultura e raça/etnia}

Aniela realizou estudos comparativos sob diversos aspectos para investigar a natureza e a manifestação das diferenças individuais e entre grupos, analisando as influências relativas à idade, ao sexo, ao meio social, à origem nacional, à cultura e ao fator étnico-racial. Os processos migratórios, as relações étnico-raciais, as atitudes e os interesses de jovens de diferentes culturas, e os processos inter e intraculturais estavam no centro de suas investigações. Influenciada pela agenda antirracista do pós-guerra, Aniela tinha a preocupação de detectar as especificidades étnico-raciais, culturais e nacionais, para compreender as diferenças e questionar a universalidade do saber psicológico (Azevedo, 2002).

Para a pesquisadora, eram necessárias teorias sociais que pudessem abranger as diferenças individuais, de aptidões e de meio cultural sobre o comportamento. Desse 
modo, compreendia que os estudos interculturais possibilitavam separar os aspectos gerais da personalidade humana das características induzidas culturalmente, ou seja, auxiliavam na formação de leis gerais do comportamento humano e na observação dos efeitos de fatores controladores do meio sobre o desenvolvimento de aptidões e de atitudes em culturas contrastantes (Ginsberg, 1973b, p. 122).

De acordo com Anastasi (1937, citada por Ginsberg, 1953b), as diferenças individuais são de natureza quantitativa, e não qualitativa, isto é, diversos graus de uma mesma característica estão distribuídos na população com uma tendência central. Sendo assim, as "variáveis externas" parecem influir mais que a hereditariedade na configuração de diferenças e particularidades: "As diferenças entre indivíduos pertencentes a grupos heterogêneos parecem ser causadas mais por fatores do meio. Nas diferenças individuais, dentro de grupos mais homogêneos, os fatores de hereditariedade parecem ser preponderantes" (Ginsberg, 1953b, p. 212).

Em relação às diferenças sexuais, por exemplo, Aniela defende que elas também podem ser explicadas pela diversidade do meio social, apesar da influência dos aspectos físicos no comportamento de homens e mulheres; e dialoga com a noção de gênero: desde o início da socialização, essas diferenças de comportamento são exageradas pela cultura, atribuindo-se a oposição de caracteres masculinos e femininos, que "não são sexuais, mas sociais" (Ginsberg, 1953b, p. 223), construídos e atualizados a todo o momento, devido às diferentes condições de poder, meios sociais e educacionais de homens e mulheres.

A raça/etnia também é abordada em seus estudos comparativos por um viés culturalista ou ambientalista. Aniela entende raça, a partir da definição de Klineberg ${ }^{3}$ (1940, citado por Ginsberg, 1953b, p. 227), como um "grupo de pessoas de tipo físico semelhante e hereditariedade comum".

A comparação entre raças/etnias e nacionalidades constitui, para Aniela, o maior desafio da psicologia diferencial e intercultural, em razão da pouca precisão da terminologia empregada e das grandes dificuldades experimentais. Comparar os diferentes grupos étnico-raciais e nacionais apresenta problemas metodológicos como a necessidade de formar grupos análogos com pessoas de raças/ etnias ou nacionalidades distintas, a diferença étnico-racial entre examinador e examinando, as diferenças linguísticas, educacionais e socioeconômicas entre indivíduos, e de cultura e tradição entre os diversos grupos, o que pode dificultar sobremaneira a precisão e a análise desses estudos.

3 Entre 1945 e 1947, Otto Klineberg da Columbia University permaneceu no Brasil para difundir as experiências norte-americanas no campo da Psicologia Social e para criar o Departamento de Psicologia da USP. Foi consultor da Unesco no delineamento da pesquisa sobre relações inter-raciais no Brasil (Maio, 2010). Klineberg convida Aniela Ginsberg (entre outros autores) para participar de seu livro Psicologia Moderna (1953) e a indica como uma das pesquisadoras em psicologia social para o Projeto Unesco.
No que concerne às classificações étnico-raciais utilizadas por Aniela nos inquéritos de pesquisa, dois fatores merecem destaque: a heteroclassificação e a utilização da "aparência racial" como critério. Todos seus estudos de raça/etnia foram realizados com base na heteroclassificação: os participantes eram classificados por observadores, e não pela autodeclaração, o que é mais difundido nas pesquisas atuais sobre a temática racial. Em geral, as classificações étnico-raciais da autora utilizavam apenas aspectos físicos como critério - cor da pele, dos olhos e dos cabelos; forma dos cabelos; dimensões do corpo; índice cefálico; medidas faciais (largura do nariz, capacidade craniana); grupos sanguíneos e preponderância da atividade de certas glândulas endócrinas.

Embora essas classificações fossem feitas com base na aparência física, seguem convenções distintas nos diversos estudos. Em um estudo realizado em 1947, as crianças foram classificadas, de acordo com a convenção sugerida por Otto Klineberg, em: a) completamente brancos; b) não completamente brancos; c) mulatos; d) não completamente pretos; e) completamente pretos (Ginsberg, 1947b). Em outro estudo (Ginsberg, 1950a), alunos de escolas públicas foram classificados, por três observadores independentes, como brancos ou quase-brancos, ou como pretos ou quase-pretos, e, ainda, em um estudo de 1951, os participantes foram divididos em seis categorias: a) completamente brancos; b) mulatos claros; c) mulatos; d) negros, mas com alguma mistura com brancos; e) negros; f) indígenas ou com alguma descendência indígena (Ginsberg, 1951).

A autora considera, porém, que as classificações e, principalmente, as tentativas de associar características físicas e psíquicas eram falhas, já que "não foi possível demonstrar que as diferenças psíquicas significativas estejam associadas aos característicos físicos, usados como critério para classificações raciais" (Klineberg, 1940, citado por Ginsberg, 1953b, p. 230). Sendo assim, as diferenças entre os grupos étnico-raciais - assim como as diferenças de inteligência, de idade, entre a população urbana e rural, e entre os sexos - devem-se à diversidade sociocultural e não a aspectos raciais ou a variáveis internas do indivíduo, como suas características físicas e psicológicas: "até agora os estudos feitos não conseguiram demonstrar a existência de diferenças raciais inatas, independentes das influências do meio" (Ginsberg, 1953b, p. 233).

O Brasil, principalmente a Bahia, constituía-se em um terreno muito favorável para estudos sobre grupos étnico-raciais, já que era possível comparar as realizações de pessoas de raças/etnias distintas, mas que falavam a mesma língua, que cresceram no mesmo meio físico, geográfico e social, e que não raro frequentavam a mesma escola, entre outros espaços de convívio e sociabilidade. Isso motivou Aniela a estudar, por exemplo, as diferenças entre jovens negros e brancos, pertencentes ao mesmo meio social baiano (Ginsberg, 1950a).

No início da década de 1950, para o Projeto Unesco, Aniela realizou o estudo Pesquisas sobre as Atitudes de um Grupo de Escolares de São Paulo em Relação com as 
Crianças de Cor (Ginsberg, 1955), em que procurou analisar: a) se no meio escolar existia preconceito de raça/etnia, quais suas formas e graus; b) qual a atitude de crianças de idade escolar em relação aos colegas brancos e de cor; c) se existiam atitudes hostis devido às diferenças étnico-raciais d) se as crianças podiam se identificar com seus respectivos grupos e) se havia modificações dessas atitudes com relação à idade, ao sexo, ao meio social e à cor ou raça/ etnia das crianças.

Para isso, foram analisadas as atitudes das crianças em um jogo com bonecas idênticas, uma branca e outra preta, e a interpretação pelas mesmas crianças de quadros ilustrativos de cenas cotidianas da vida de crianças brancas e negras, como medidas indiretas que possibilitassem 0 acesso ao preconceito de raça/etnia. No decorrer do jogo lúdico, eram feitas perguntas na tentativa de identificar se as crianças consideravam as bonecas como iguais ou diferentes; quais as diferenças constatadas pelas crianças; quais as relações entre essas bonecas; a preferência das crianças por uma das bonecas; e as respectivas justificativas das respostas dadas. Nos quadros ilustrativos, eram apresentadas cenas de crianças ou jovens, negros e brancos, às vezes interagindo entre si e às vezes separados, de forma mais ou menos radical. O primeiro desses quadros ilustrava, por exemplo, um grupo de crianças brincando com a água e a única criança negra distante do grupo. Após a apresentação deste quadro, eram feitas as seguintes perguntas: "Que fazem estas crianças? E este menino (negro), brinca com os outros ou está sozinho?" Se a criança responder que está sozinho, "Por quê?".

Neste ponto, é importante ressaltar a extrema desigualdade entre negros e brancos na década de 1950, refletida nos subgrupos formados pelos participantes dessa pesquisa. Negros(as) e "mulatos(as)" eram minoria nas escolas secundárias, mesmo em cidades onde eram a maioria da população - nas escolas pesquisadas eram apenas 19,7\% dos alunos (Ginsberg, 1955). Como afirma Bastide, ao apresentar os resultados do Projeto Unesco em São Paulo (Bastide \& Fernandes, 1955, p.11), o preconceito de cor serve à manutenção das desigualdades e justifica a opressão e a dominação social e racial, o que é demonstrado pelo escasso acesso de negros e negras à educação e por sua necessidade de inserção em outras atividades, em geral remuneradas, desde a infância.

Sendo assim, as desigualdades existentes no Brasil não eram (e não são) apenas de ordem socioeconômica, mas fortemente influenciadas pelo fator étnico-racial. Nos estudos de Aniela, cor e raça/etnia aparecem como um indicador importante para compreender a produção sociocultural das diferenças e desigualdades, não pela ação da hereditariedade, mas por sua interação com o meio social brasileiro, marcado por certa segregação étnico-racial e pelo papel social inferior atribuído a negros e negras.

A linguagem é outro forte elemento de manifestação das desigualdades étnico-raciais, evidenciado no desenvolvimento dos próprios estudos de Aniela e no uso dos termos atribuídos aos sujeitos de pesquisa. Negros e negras são denominados pessoas de cor, considerando-se a brancura como neutra e/ou natural e as pessoas negras a partir da negação, como "não brancos". No estudo para o Projeto Unesco, a autora observa que a maioria das crianças brancas empregava a palavra "moreno" para referir-se ao "mulato", enquanto dentre os adultos esta denominação era utilizada, principalmente pelos próprios mulatos, "talvez para esconder a origem negra de sua cor" (Ginsberg, 1955, p. 331).

Os resultados de um estudo realizado por Aniela sobre a escolha dos companheiros de carteira em sala de aula (Ginsberg, 1947b) sugerem que as crianças escolhem o companheiro de carteira e os amigos, de maneira mais ampla, com base nas características semelhantes ou na identificação. As crianças completamente brancas, porém, parecem ter certo prestígio: são escolhidas com maior frequência por crianças de outras cores.

O fator étnico-racial e o racismo aparecem como explicação secundária das atitudes e escolhas das crianças nesses estudos (Ginsberg, 1947b, 1955). No entanto, crianças brancas e negras atribuíram frequentemente um papel social inferior a negros e negras, demonstrando uma preferência pelas crianças brancas. Pode-se, então, questionar até que ponto essas escolhas, naturalizadas, já foram influenciadas por fatores educacionais, sociais e políticos, atravessados pelo estereótipo da população negra e pela desigualdade étnico-racial. A preferência por brancos e "mulatos" pode ser uma marca do ideal branco e da crença na superioridade socioeconômica e étnico-racial desse grupo. Sendo assim, observa-se que tanto o estereótipo do negro, rebaixado social e economicamente, como o ideal branco e a branquitude - isto é, a percepção ou não dos brancos sobre sua identidade étnico-racial - são naturalizados pela educação familiar no imaginário de crianças (negras e brancas) desde muito pequenas.

Os estudos sobre raça/etnia realizados com crianças e jovens por Aniela nas décadas de 1940 e 1950 (Ginsberg, 1947a, 1947b, 1950a, 1950b, 1951，1953a, 1955) demonstram diferenças entre os resultados médios dos grupos de brancos e negros, ainda que pequenas e estatisticamente pouco significativas. Os resultados do estudo Comparação Entre os Resultados de um Teste de Nivel Mental Aplicado em Diferentes Grupos Étnicos e Sociais (Ginsberg, 1951) mostraram que, em todos os grupos sociais, os alunos brancos obtiveram os melhores resultados, seguidos pelos "mulatos claros" (quase brancos), pelos "mulatos" em geral, pelos indígenas ou descendentes de indígenas e, por último, pelos alunos negros ou "quase negros". As diferenças entre as notas médias de crianças brancas e negras e de crianças brancas e indígenas foram significativas. Em geral, o grupo de jovens brancos tinha um nível mental levemente superior, com uma mentalidade mais teórica; os jovens brancos eram menos inibidos, com uma afetividade mais expansiva e egocêntrica. Os jovens negros, por outro lado, demonstraram uma mentalidade mais prática, com menos estereotipia e com maiores capacidades criadoras. Os resultados 
parecem indicar mais diferenças intelectuais que afetivas (Ginsberg, 1950a).

Para Aniela, "esta inferioridade relativa dos pretos em todos os meios estudados é um fenômeno difícil de ser explicado, não dependendo diretamente nem do meio nem da hereditariedade" (Ginsberg, 1951, p. 41). A diferença de nível intelectual encontrada pode refletir as diferentes habilidades de brancos e negros, mas também (e principalmente) a influência dos processos educacionais e das histórias de reforçamento para os indivíduos de raças/etnias distintas. Assim, essas diferenças entre jovens negros e brancos podem ser mais devidas às diferenças individuais de personalidade e de trajetória de desenvolvimento que a diferenças étnico-raciais inatas. Contudo, ainda que Aniela se preocupe em abordar cor e raça/etnia como categorias de análise para além da classe social, ela não discorre sobre a possibilidade de o racismo ser um dos motivos das diferenças encontradas entre os grupos étnico-raciais.

Nas décadas de 1940 e 1950, Aniela estava voltada para o estudo das diferenças individuais e entre grupos encontradas nos resultados de testes projetivos e de nível mental: nesse contexto, interessava-se mais pela influência do fator étnico-racial, e os conceitos de raça/etnia e de cultura apareciam entrelaçados e menos diferenciados. Nas décadas seguintes, porém, a autora volta-se ainda mais para os estudos inter e intraculturais, procurando isolar as influências dos fatores étnico-racial e cultural dentro das características de personalidade e das motivações.

Assim, a partir das décadas de 1960 e 1970, Aniela começa a diferenciar raça/etnia e cultura em seus estudos. Enquanto o conceito de raça/etnia parece estar relacionado à origem nacional ou mais propriamente à hereditariedade, o conceito de cultura parece ser mais amplo e abranger influências provenientes de diferentes raças/etnias, mas que dialogam numa mesma cultura, como é o caso da "cultura africana" ou da "cultura ocidental". Sendo assim, ter a mesma origem étnico-racial não significa necessariamente possuir as mesmas influências culturais, e vice-versa.

No início da década de 1970, Aniela procurou investigar, por exemplo, em que medida as diferenças socioeconômicas e culturais influenciavam as atitudes e a personalidade de jovens universitários (do sexo masculino) de três países muito diferentes: Brasil, Japão e Polônia. Os participantes foram divididos em grupos com base no nível educacional dos pais (universitário, nível colegial, secundário inferior e primário inferior completo ou incompleto), e em sua origem nacional. Diferenças entre os grupos nacionais foram estatisticamente significativas com maior frequência que aquelas provocadas por fatores socioeconômicos (de acordo com o nível educacional ou de instrução dos pais). Comparando os grupos nacionais entre si, as respostas de jovens brasileiros e poloneses ao teste de Holtzman foram muito mais próximas que as respostas desses grupos em relação às dos jovens japoneses. Dessa maneira, esse estudo (Ginsberg, 1973b) indicou a influência de fatores históricos e culturais sobre aspectos da personalidade: Brasil e Polônia são países bastante diferentes quanto à origem étnico-racial da população, ao idioma, às condições geográficas e sociais, mas ambos são países católicos e historicamente influenciados pela "cultura ocidental"; o que parece ter conduzido a certa similaridade entre os jovens desses países.

Em outro estudo (Ginsberg, 1973a), buscou diferenciar a influência dos fatores étnico-racial e cultural sobre as aspirações profissionais dos jovens e sobre certos aspectos de personalidade. Aniela formou, para tanto, uma amostra de participantes nascidos e criados no Brasil, imersos na cultura brasileira; mas provenientes de dois grupos étnico-raciais distintos: filhos de japoneses e filhos de brasileiros (há mais de três gerações). A Escala Cantril ${ }^{4}$ não demonstrou diferenças significativas entre os grupos étnico-raciais, já o T.A.T. ${ }^{5}$ demonstrou uma diferença significativa de personalidade entre os membros dos dois grupos: os descendentes de japoneses pareceram ser "mais capazes de adiar a satisfação de seus desejos e apresentaram maiores níveis de ansiedade" (Ginsberg, 1973a, p. 83), se comparados aos brasileiros. Pelos resultados do teste de Holtzman ${ }^{6}$, os brasileiros pareceram "mais maduros e intelectualmente mais flexíveis, mais críticos e com tendência ao raciocínio mais abstrato, porém mentalmente mais indolentes, tendendo a dar respostas mais fáceis". Os japoneses, por outro lado, pareceram ser "mais rígidos e mais convencionais, sendo mais dependentes das normas do grupo" (Ginsberg, 1973a, p. 84).

Aniela questiona se essas diferenças encontradas, principalmente quanto à maior ansiedade, rigidez e adesão às normas convencionais pelos descendentes de japoneses, devem-se ao fator étnico-racial ou ao próprio processo imigratório. Estudos citados por ela (Ginsberg, 1973a, p. 84) mostraram que a segunda e a terceira gerações de imigrantes, em geral, são mais "inseguras e neuróticas" que os próprios imigrantes, devido aos conflitos entre os valores dos dois grupos culturais.

Destarte, Aniela propôs outro estudo com imigrantes para analisar a relação entre a influência cultural do país de origem e do país de destino da imigração, adotando, para isso, os conceitos de aculturação - modificação no esquema total de valores, devido à integração na cultura do país de destino, abrangendo a linguagem, as amizades, a religião e os interesses culturais - e de adaptação social - relacionado a dificuldades pessoais, "causadas pelo fato de viver sobre a influência de dois diferentes conjuntos de normas e de valores sociais" (Ginsberg, 1978b, p. 136). Os participantes foram divididos em três grupos: brasileiros (de quatro ou mais gerações), nisseis (nascidos no Brasil) e japoneses nascidos no Japão; e os resultados foram

4 Na primeira parte, avalia as tendências para otimismo ou pessimismo, com o qual os sujeitos encaram sua situação atual e futura, comparada ao seu passado; a segunda consiste na descrição pelos sujeitos de seus maiores desejos e temores relacionados ao seu futuro (Ginsberg, 1978, p. 9).

5 Os sujeitos deveriam estabelecer uma ordem em conjuntos de três desenhos (envolvendo estudos e atividades profissionais) e escrever uma história sobre um personagem principal.

6 Teste projetivo amplamente usado em pesquisas interculturais - fonte de informação sobre os aspectos da personalidade dos sujeitos e sobre algumas atitudes interpessoais (Ginsberg, 1978, p. 8). 
comparados, procurando as principais semelhanças e diferenças entre os grupos. Os testes (Holtzman, Escala de Cantril, Questionário de Filosofia de Vida ${ }^{7}$ e Questionário Biográfico) demonstraram grande semelhança entre os nisseis e os brasileiros, e semelhança muito menor com os resultados dos japoneses. Em relação à aculturação e à adaptação social, os nisseis menos aculturados evidenciaram alguns sinais de tensão, como "um desejo exagerado de contato com os outros, um desejo de 'pertencer', uma ansiedade controlada; medo de malogro profissional, forte afetividade . . . socialmente controlada, preocupação com seu dever e pouca independência do julgamento" (Ginsberg, 1978b, p. 145). Já os imigrantes mais bem adaptados revelaram maior independência em relação aos outros e aos julgamentos, permitindo a realização de seus planos e, com isso, uma vida interior mais rica, menor vulnerabilidade e maior facilidade para se adaptar ao novo país.

Nesses estudos (Ginsberg, 1973a, 1973b, 1978b), mais uma vez, Aniela procura controlar outras variáveis que poderiam influenciar os resultados, nivelando a idade, o sexo e o nível socioeconômico e educacional dos participantes; além de aplicar diferentes testes para obter dados mais amplos e complexos. Também reforça o interesse por compreender os processos migratórios e as atitudes e os interesses de jovens de diferentes raça/etnias e culturas, mediante estudos inter e intraculturais.

\section{Contribuições e limitações dos estudos de Aniela Ginsberg na área de intercultura e raça/etnia}

A principal contribuição de Aniela para os estudos em psicologia na área de intercultura e raça/etnia é metodológica. Segundo ela, a psicologia social se utilizava de uma grande variabilidade de métodos não estruturados que podiam levar a diferenças nos resultados obtidos (Ginsberg, 1978a, p. 6). Por isso, os diferentes testes e métodos utilizados em seus estudos - Rorschach, Mira y López $^{8}$ (PMK), Catálogo de Livros ${ }^{9}$, Escala de Aspirações de Cantril, T.A.T Especial, Teste de Borrões de Tinta de W. Holtzman (HIT), Questionário de Filosofia de Vida de Díaz Guerrero, Medida da distância social de Bogardus ${ }^{10}$

7 Mede as atitudes ativas ou passivas ao enfrentar as adversidades da vida (Ginsberg, 1978, p. 9).

8 Avalia características estruturais e reacionais de personalidade, a partir da análise de tensões musculares involuntárias dos braços em diferentes orientações espaciais (Vasconcelos, 2011).

9 As crianças deveriam escolher 15 títulos de livros que desejassem ler, dentre uma lista de 100 títulos apresentados, e indicar os cinco que considerassem mais interessantes, numerando-os de 1 a 5 .

10 Os sujeitos deveriam escolher, dentre uma lista de diferentes grupos nacionais e étnico-raciais, membros que aceitariam como parente de casamento, membro do clube ou do círculo de amigos, vizinho de rua, membro do seu grupo profissional, cidadão de seu país, turista de seu país, ou excluiria de seu país. e o Método Sociométrico ${ }^{11}$ - aparecem como ferramentas que permitem a comparação criteriosa e estruturada das semelhanças e diferenças entre os indivíduos e grupos (de diferentes origens étnico-raciais, idades, meios sociais, gêneros etc.) em seus inúmeros estudos inter e intraculturais. Além disso, Aniela costumava combinar diferentes testes em uma mesma pesquisa, pois assim encontrava-se frente a um número de relações mais complexas, podendo concentrar-se nas variáveis que fazem a diferença (Ginsberg, 1978a, p. 6). Nesse sentido, seus estudos surpreendem pela inovação tecnológica e pelo rigor científico.

A metodologia aparece, portanto, como resposta às questões de pesquisa: é a partir dos diferentes métodos que a pesquisadora pretende cercar todas as variáveis. No estudo com jovens baianos (Ginsberg, 1950a), por exemplo, Aniela preocupou-se em diminuir os efeitos de variáveis intervenientes, isolando unicamente a influência do fator étnico-racial: os jovens foram agrupados em pares, constituídos por um negro e outro branco, em que ambos deveriam ser do mesmo sexo, frequentar a mesma escola e a mesma classe, ter o mesmo aproveitamento escolar e a mesma idade, e pertencer ao mesmo meio social, com base na profissão dos pais.

Apesar de utilizar amplamente os testes em seus estudos, a crítica a suas características sempre foi uma preocupação de Aniela. Interessou-se, por exemplo, em analisar se a superioridade das crianças brancas de meios privilegiados era resultado unicamente de diferenças de inteligência ou devida a outras causas relacionadas à elaboração dos próprios testes frequentemente aplicados. Os resultados desses estudos (Ginsberg, 1951, 1953a) indicaram a dependência entre os interesses dos jovens e seu meio social. Sendo assim, os testes de inteligência (mesmo os não verbais) e de personalidade são, em geral, elaborados especialmente para crianças de meios sociais economicamente mais abastados (com frequência brancas), solicitando mais seus interesses, e desconsiderando os interesses e o universo simbólico mais significativo de crianças pertencentes às classes sociais de menor poder aquisitivo que, em geral, obtêm os piores resultados médios nesses testes.

A partir de outro estudo (Ginsberg, 1947a, p. 83), com os índios Kaingang, Aniela afirma também que a aplicação dos testes projetivos (de Rorschach e Mira y López) em um ambiente desconhecido pelos nativos provavelmente não contribuiu para seu "bem-estar psíquico". As pranchas do teste de Rorschach eram encaradas com estranhamento e chocavam os Kaingang, distantes que eram de sua cultura e de suas vivências cotidianas, demonstrando o viés cultural deste teste. Conclui-se, portanto, que as diferenças entre os resultados de indivíduos de diferentes raças/etnias, culturas e classes sociais, dentre outras características, nos mais diversos testes utilizados por Aniela podem ser

11 As crianças deveriam escrever em um papel ou dizer em voz baixa o nome do menino ou menina que gostariam de ter como companheiro de carteira. Depois deveriam escolher uma segunda criança. E, por fim, deveriam dizer a razão dessa escolha. 
atribuídas, em grande parte, às características intrínsecas aos próprios testes, enviesados e culturalmente restritivos.

A investigação da história do pensamento psicológico sobre relações étnico-raciais ajuda a compreender a gênese da psicologia e sua atualidade na produção de sistemas de interpretação de mundo e de ser humano (Santos, Schucman, \& Martins, 2012). Nesse sentido, intriga o fato de a produção de Aniela ser tão pouco conhecida e distante mesmo dos pesquisadores das relações étnico-raciais, visto o lugar de destaque que ela ocupou em seu período, atuando na construção e na consolidação do campo de pesquisas e práticas de psicologia social no Brasil e sendo, inclusive, convidada a participar do livro de Klineberg e dos estudos do Projeto Unesco - marco das ciências humanas na compreensão das relações raciais no Brasil, ainda hoje amplamente lidos e discutidos dentro e fora da academia. Por que, então, a produção de Aniela teve um destino tão diferente daqueles com quem trabalhou neste audacioso projeto? Por que seus estudos sobre raça/etnia não floresceram e se fortaleceram na psicologia brasileira?

Essas questões transcendem o objetivo desse artigo e apontam para a necessidade de novas investigações. Os estudos de Aniela na área de raça/etnia não foram levados adiante ou tomados como referência para pesquisas posteriores, nem por aqueles com quem a pesquisadora trabalhou, sobretudo no Projeto Unesco. Os profissionais e pesquisadores formados e/ou orientados por Aniela, em sua maioria, apreenderam especialmente os métodos e as técnicas de psicodiagnóstico, ensinados por ela nos cursos de Psicologia, adaptando-os a seus diversos objetos de interesse; ou ainda, voltaram-se aos estudos interculturais e comparativos de personalidade e de interesses profissionais, porém, distanciados da temática racial.
A produção de Aniela na área de raça/etnia, em grande medida, limitou-se a descrever os fenômenos observados, pouco contribuindo para desvelar o caráter projetivo do preconceito, e sem se fundamentar em uma teria capaz de explicar os efeitos psicossociais desse fenômeno. Isso em um momento em que os estudos de Adorno (1965), como A personalidade autoritária, já eram amplamente reconhecidos pela comunidade científica como importantes para a compreensão dos mecanismos inerentes ao preconceito. Ao contrário da produção daqueles com quem trabalhou no Projeto Unesco, os estudos de raça/etnia de Aniela não trouxeram novos elementos para a compreensão do preconceito étnico-racial no Brasil de forma a fomentar as iniciativas dos movimentos negros que começavam a se organizar em sua época e, principalmente, que fossem capazes de desvendar o sentido psicológico e a natureza eminentemente política do racismo.

Destarte, Aniela Ginsberg permanece como uma personagem importante da história do pensamento psicológico brasileiro. Seus estudos de raça/etnia configuram-se como estudos intraculturais da sociedade brasileira e de suas amplas diversidades. A pesquisadora demonstrou a importância do rigor científico e da metodologia para o desenvolvimento de estudos inter e intraculturais. E procurou desconstruir a visão determinista biológica das raças/etnias que prevalecia até então e mostrar que é na interação dos indivíduos com os grupos e com a sociedade que as diferenças podem transformar-se em desigualdades, ou seja, que as diferenças são mais construções socioculturais que fruto da hereditariedade.

\title{
Aniela Meyer Ginsberg and the studies of race/ethnicity and interculture in Brazil
}

\begin{abstract}
This essay outlines the contributions of Aniela Meyer Ginsberg (1902-1986) for the ethnic-racial and intercultural studies in Brazil. Her productions on these topics - including articles, book chapters and conferences - were our main object of interest. Influenced by the anti-racist agenda of the post-war, inter and intracultural processes, ethnic-racial relations and migration were at the center of her investigations. Aniela is an important character in the history of Brazilian psychological thinking; her studies on race/ethnicity in Brazil are characterized as intracultural studies of national society and its wide diversities. She sought to deconstruct the biological determinist view of the races/ethnicities and show that is in the interaction between individuals and the society that the differences can turn into inequalities.
\end{abstract}

Keywords: Aniela Meyer Ginsberg, race and ethnicity, interculture, Social Psychology, History of Psychology - Brazil.

\section{Aniela Meyer Ginsberg et les études de race/ethnie et interculture au Brésil}

Résumé: Cet article décrit les contributions d'Aniela Meyer Ginsberg (1902-1986) sur les études ethnicoraciales et interculturelles au Brésil. Sa production sur ces sujets - y compris des articles, des chapitres de livres et des résumés de conférences - a été notre principal objet d'intérêt. Influencée par le programme anti-raciste de l'après-guerre, les processus inter et intraculturels, les relations ethnicoraciales et la migration étaient au centre de ses investigations. Aniela est un personnage important dans I'histoire de la pensée psychologique brésilienne, ses études sur la race/ethnie au Brésil sont caractérisées comme des études intraculturelles de la société nationale et ses larges diversités. L'auteur se propose de déconstruire la vision déterministe bi- 
ologique des races/ethnies et montrer qui est dans l'interaction entre les individus et la société que les différences peuvent se transformer en inégalités.

Mots-clés: Aniela Meyer Ginsberg, race et ethnie, interculture, Psychologie Sociale, Histoire de la Psychologie - Brésil.

\section{Aniela Meyer Ginsberg y los estudios de raza/etnia y intercultura en Brasil}

Resumen: Este artículo resume las contribuciones de Aniela Meyer Ginsberg (1902-1986) para el estudio de las relaciones étnico-raciales e interculturales en Brasil. Su producción en estos temas - incluyendo artículos, capítulos de libros y resúmenes de congresos - fue nuestro principal objeto de interés. Bajo la influencia de la agenda anti-racista de lo post-guerra, los procesos intra y interculturales, las relaciones étnico-raciales y la migración están en el centro de sus investigaciones. Aniela es un personaje importante en la historia del pensamiento psicológico brasileño, sus estudios sobre la raza/etnia en Brasil se caracterizan por ser estudios intraculturales de la sociedad nacional y su amplia diversidad. La autora trató de deconstruir la visión determinista biológica de las razas/etnias y mostrar que es en la interacción de los individuos con la sociedad que las diferencias pueden convertirse en desigualdades.

Palabras clave: Aniela Meyer Ginsberg, raza y etnia, intercultura, Psicología Social, Historia de la Psicología - Brasil.

\section{Referências}

Adorno, T. W. (1965). La personalidad autoritaria. Buenos Aires: Proyección.

Azevedo, M. L. B. (2002). A obra de Aniela Ginsberg: uma contribuição para a história da Psicologia Social no Brasil (Tese de Doutorado). Pontifícia Universidade Católica, São Paulo, SP.

Baptista, M. T. D.S. (2010). A regulamentação da profissão Psicologia: documentos que explicitam o processo histórico. Psicologia: Ciência e Profissão, 30(spe), 170-191.

Bastide, R., \& Fernandes, F. (1955). Relações raciais entre negros e brancos em São Paulo. São Paulo, SP: Anhembi.

Bicudo, V. L. (1945). Estudo de atitudes raciais de pretos e mulatos em São Paulo (Dissertação de Mestrado). Escola de Sociologia e Política de São Paulo, SP.

Bosi, E. (2000). Dante Moreira Leite: Mestre da Psicologia Social. Psicologia USP, 11(2), 15-23.

Forghieri, Y. C. (2011, Julio-Diciembre). Aniela Meyer Ginsberg (*02/10/1902 - +03/08/1986) inolvidável pesquisadora, antecessora da Cad. $\mathrm{n}^{\mathrm{o}} 11$. Boletim Academia Paulista de Psicologia, 351-357.

Ginsberg, A. M. (1947). Aplicação do Psicodiagnóstico de Rorschach a Índios Kaingang. Separata da Revista do Museu Paulista, 1, 75-106.

Ginsberg, A. M. (1947). Escolha do companheiro de carteira: resultado de um inquérito entre escolares bahianos. Psyke: Revista Didática e Científica de Psicologia, Psiquiatria e Psicoanálise, 1(3), 3-17.

Ginsberg, A. M. (1950). Um estudo de 100 jovens bahianos com o Teste de Rorschach. Neurobiologia, 13(1), 1-50.

Ginsberg, A. M. (1950). Um inquérito sobre as atitudes de estudantes baianos em relação a diversos grupos nacionais e raciais. Boletim de Psicologia, 1(4), 10-15.

Ginsberg, A. M. (1951). Comparação entre os resultados de um teste de nível mental aplicado em diferentes grupos étnicos e sociais. Arquivos Brasileiros de Psicotécnica, 4(4), 27-44.

Ginsberg, A. M. (1953). Estudo comparativo dos interesses dos adolescentes de diferentes meios sociais. Arquivos Brasileiros de Psicotécnica, 5(4), 7-31, Rio de Janeiro.

Ginsberg, A. M. (1953). Psicologia diferencial. In O. Klineberg, A psicologia moderna (pp. 204-237), São Paulo, SP: Agir.

Ginsberg, A. M. (1955). Pesquisas sobre as atitudes de um grupo de escolares de São Paulo em relação com as crianças de cor. In R. Bastide \& F. Fernandes, Relações raciais entre negros e brancos em São Paulo (2a ed., pp. 311-361). São Paulo, SP: Anhembi.

Ginsberg, A. M. (1973). Um estudo comparativo de aspirações culturais e profissionais em estudantes brasileiros de diferentes origens étnicas. Revista de Psicologia Normal e Patológica, 19(1-4), 74-98. (Republicado na Revista Interamericana de Psicologia, n. 1, 1974)

Ginsberg, A. M. (1973). Um estudo comparativo da personalidade de jovens universitários pertencentes a três diferentes grupos culturais. Anais do XVI Congresso Interamericano de Psicologia, pp. 122-135.

Ginsberg, A. M. (1973). Significado de estudos interculturais para a psicologia. Anais do XIV Congresso Interamericano de Psicologia, p. 101.

Ginsberg, A. M. (1978). Proposição do problema e descrição da pesquisa. In A. M. Ginsberg, um estudo inter $e$ intracultural: atitudes e personalidade de universitários (pp. 3-13). São Paulo, SP: Cortez \& Moraes.

Ginsberg, A. M. (1978). Aculturação e adaptação - nisseis, japoneses e outros brasileiros. In A. M. Ginsberg, um estudo inter e intracultural: atitudes e personalidade de universitários (pp. 134-146). São Paulo, SP: Cortez \& Moraes. 
Ginsberg, A. M. (1978). Estudos intraculturais. In A. M. Ginsberg, um estudo inter e intracultural: atitudes $e$ personalidade de universitários (pp. 147-160). São Paulo, SP: Cortez \& Moraes.

Graciano, M. (1976). Dante Moreira Leite face a preconceitos e ideologias sobre caráter nacional. Cadernos de Pesquisa, 17, 9-12.

Guimarães, A. S. A. (2003). Como trabalhar com "raça" em sociologia. Educação e Pesquisa, 29, 93-107.

Leite, D. M. (1954). O caráter nacional brasileiro (Tese de Doutorado). Faculdade de Filosofia, Ciências e Letras da Universidade de São Paulo, SP.

Leite, D. M. (1966). Psicologia diferencial. São Paulo, SP: Desa.

Maio, M. C. (1999). O Projeto Unesco e a agenda das ciências sociais no Brasil dos anos 40 e 50. Revista Brasileira de Ciências Sociais, 14(41).

Maio, M. C. (2010). Educação sanitária, estudos de atitudes raciais e psicanálise na trajetória de Virgínia Leone Bicudo. Cadernos Pagu, 35, 309-355.
Martins, H. V., Araújo, L. G., Folly, E., Vilar, F., Araújo, K. C., Damasceno, H. N. (2011). A produção científica em psicologia no Brasil e a questão racial: apontamentos iniciais. (Apresentação oral). Recuperado de http:// www.encontro2011.abrapso.org.br/trabalho

Paiva, G. J. (2000). Dante Moreira Leite: um pioneiro da psicologia social no Brasil. Psicologia USP, 11(2), 25-57.

Pimentel, A. (2001). O método da análise documental: seu uso numa pesquisa historiográfica. Cadernos de Pesquisa, 114, 179-195.

Ramos, A. (1948). Os grandes problemas da Antropologia brasileira. Sociologia, 10(4), 213-226.

Santos, A. O., Schucman, L. V., \& Martins, H. V. (2012). breve histórico do pensamento psicológico brasileiro sobre relações étnico-raciais. Psicologia: Ciência $e$ Profissão, 32, 166-175.

Vasconcelos, A. G., Nascimento, E., \& Sampaio, J. R. (2011). PMK: validade preditiva do PMK em relação à presença de sintomas psicopatológicos. Psico-USF, 16(2), 143-149. 


\section{ANEXOS}

Quadro 1

Organização da produção de Aniela Ginsberg sobre relações étnico-raciais e interculturais.

Título e Ano de Publicação

\section{Objetivo(s) de pesquisa}

\section{População Sob Estudo}

\section{Vocabulário utilizado para se referir aos grupos étnico-raciais}

\begin{tabular}{|c|c|c|c|c|c|}
\hline $\begin{array}{l}\text { Escolha do } \\
\text { Companheiro } \\
\text { de Carteira - } \\
\text { Resultado de } \\
\text { um Inquérito } \\
\text { entre Escolares e } \\
\text { Bahianos (1947) }\end{array}$ & $\begin{array}{l}\text { Psyke - Revista } \\
\text { Didática e } \\
\text { Científica de } \\
\text { Psicologia, } \\
\text { Psiquiatria e } \\
\text { Psicoanálise }\end{array}$ & $\begin{array}{l}\text { Investigar quais as } \\
\text { influências relativas } \\
\text { à idade, ao sexo e } \\
\text { à raça na escolha, } \\
\text { pelo aluno, de seu } \\
\text { companheiro de } \\
\text { carteira. }\end{array}$ & $\begin{array}{l}\text { Sociométrico: As } \\
\text { crianças escolhem } \\
\text { (escrevendo em um } \\
\text { papel ou dizendo } \\
\text { em voz baixa) dois } \\
\text { meninos ou meninas } \\
\text { que gostariam de ter } \\
\text { como companheiro de } \\
\text { carteira, por ordem de } \\
\text { preferência. Depois, } \\
\text { deveriam dizer a razão } \\
\text { dessa escolha. }\end{array}$ & $\begin{array}{l}723 \text { crianças, } \\
\text { com idades entre } \\
6 \text { e } 20 \text { anos de } \\
\text { escolas públicas } \\
\text { de diferentes } \\
\text { bairros de } \\
\text { Salvador (BA) }\end{array}$ & $\begin{array}{l}\text { Heteroclassificação } \\
\text { em: a) completamente } \\
\text { brancos; b) não } \\
\text { completamente brancos; } \\
\text { c) mulatos; d) não } \\
\text { completamente pretos; e) } \\
\text { completamente pretos }\end{array}$ \\
\hline $\begin{array}{c}\text { Aplicação do } \\
\text { Psicodiagnóstico } \\
\text { de Rorschach a } \\
\text { Índios Kaingang } \\
\text { (1947) }\end{array}$ & $\begin{array}{c}\text { Separata da } \\
\text { Revista do } \\
\text { Museu Paulista }\end{array}$ & $\begin{array}{l}\text { Comparar aspectos } \\
\text { de personalidade e de } \\
\text { comportamento de } \\
\text { diferentes indivíduos } \\
\text { dentro de uma } \\
\text { mesma etnia (viés } \\
\text { intracultural) e de } \\
\text { diferentes etnias (viés } \\
\text { intercultural). }\end{array}$ & $\begin{array}{l}\text { Rorschach e Mira y } \\
\text { López }\end{array}$ & $\begin{array}{c}32 \text { indivíduos } \\
\text { Kaingang, } 24 \text { do } \\
\text { sexo masculino } \\
\text { e } 8 \text { do sexo } \\
\text { feminino, de } \\
\text { diferentes idades } \\
\text { (de } 11 \text { a } 90 \text { anos, } \\
\text { com média de } \\
\text { idade de } 38,3 \\
\text { anos) }\end{array}$ & $\begin{array}{l}\text { Kaingang "puros", } \\
\text { mestiços e brancos }\end{array}$ \\
\hline $\begin{array}{c}\text { Um Estudo } \\
\text { de } 100 \text { Jovens } \\
\text { Bahianos, com } \\
\text { o Teste de } \\
\text { Rorschach (1950) }\end{array}$ & Neurobiologia & $\begin{array}{c}\text { Estudar as diferenças } \\
\text { entre jovens negros e } \\
\text { brancos, pertencentes } \\
\text { ao mesmo meio social } \\
\text { baiano. }\end{array}$ & Rorschach & $\begin{array}{l}100 \text { alunos de } \\
\text { escolas públicas } \\
\text { de Salvador, } \\
\text { agrupados em } \\
\text { pares (um branco } \\
\text { e um negro), } \\
\text { para isolar a } \\
\text { influência do } \\
\text { fator étnico/racial }\end{array}$ & $\begin{array}{l}\text { Heteroclassificação } \\
\text { (por três observadores } \\
\text { independentes) em: } \\
\text { brancos e pretos ou } \\
\text { quase pretos }\end{array}$ \\
\hline $\begin{array}{l}\text { Um Inquérito } \\
\text { Sobre as } \\
\text { Atitudes de } \\
\text { Estudantes } \\
\text { Baianos em } \\
\text { Relação a } \\
\text { Diversos Grupos } \\
\text { Nacionais e } \\
\text { Raciais (1950) }\end{array}$ & $\begin{array}{l}\text { Boletim de } \\
\text { Psicologia }\end{array}$ & $\begin{array}{c}\text { Investigar as } \\
\text { preferências e os } \\
\text { preconceitos em } \\
\text { relação a diversos } \\
\text { grupos étnico-raciais } \\
\text { em um ambiente de } \\
\text { população mista, } \\
\text { como a cidade de } \\
\text { Salvador. }\end{array}$ & $\begin{array}{l}\text { Medida de Distância } \\
\text { Social de Bogardus }\end{array}$ & $\begin{array}{l}400 \text { estudantes } \\
\text { universitários, do } \\
\text { sexo masculino e } \\
\text { com idades de } 18 \\
\text { a } 30 \text { anos }\end{array}$ & $\begin{array}{c}\text { Os grupos foram } \\
\text { divididos por origem } \\
\text { nacional, por origem } \\
\text { étnico-racial (judeus) } \\
\text { e por cor (negros e } \\
\text { mulatos). }\end{array}$ \\
\hline
\end{tabular}

Sociométrico: As crianças escolhem (escrevendo em um papel ou dizendo em voz baixa) dois meninos ou meninas que gostariam de ter como companheiro de ordem de preferência. Depois, dessa escolha.

32 indivíduos

Kaingang, 24 do sexo masculino e 8 do sexo com média de de 38

. 


\begin{tabular}{|c|c|c|c|c|c|}
\hline $\begin{array}{l}\text { Título e Ano de } \\
\text { Publicação }\end{array}$ & Fonte & $\begin{array}{l}\text { Objetivo(s) de } \\
\text { pesquisa }\end{array}$ & Método(s) Utilizado(s) & $\begin{array}{c}\text { População Sob } \\
\text { Estudo }\end{array}$ & $\begin{array}{l}\text { Vocabulário utilizado } \\
\text { para se referir aos } \\
\text { grupos étnico-raciais }\end{array}$ \\
\hline $\begin{array}{l}\text { Comparação } \\
\text { entre os } \\
\text { Resultados de } \\
\text { um Teste de } \\
\text { Nível Mental } \\
\text { Aplicado em } \\
\text { Diferentes } \\
\text { Grupos Étnicos } \\
\text { e Sociais (1951) }\end{array}$ & $\begin{array}{l}\text { Arquivos } \\
\text { Brasileiros de } \\
\text { Psicotécnica }\end{array}$ & $\begin{array}{c}\text { Investigar se os } \\
\text { resultados dos testes } \\
\text { de inteligência } \\
\text { variavam de maneira } \\
\text { significativa } \\
\text { em relação aos } \\
\text { diferentes meios } \\
\text { socioeconômicos } \\
\text { dos alunos e se, } \\
\text { dentro do mesmo } \\
\text { meio social, havia } \\
\text { uma variabilidade } \\
\text { significativa entre os } \\
\text { resultados obtidos por } \\
\text { alunos de diferentes } \\
\text { grupos étnico-raciais. }\end{array}$ & $\begin{array}{l}\text { Teste de Nível Mental } \\
\text { elaborado pelo C.O.J. } \\
\text { do Departamento da } \\
\text { Criança do Ministério } \\
\text { da Educação do Rio } \\
\text { de Janeiro, a partir do } \\
\text { teste de Terman }\end{array}$ & $\begin{array}{c}2000 \text { alunos } \\
\text { de escolas } \\
\text { secundárias } \\
\text { oficiais, dos } \\
\text { Estados da } \\
\text { Bahia, Distrito } \\
\text { Federal, Ceará e } \\
\text { Rio Grande do } \\
\text { Sul. Os alunos } \\
\text { foram divididos } \\
\text { segundo a idade, } \\
\text { o sexo, a classe } \\
\text { econômica e a } \\
\text { aparência racial. }\end{array}$ & $\begin{array}{l}\text { Heteroclassificação } \\
\text { em: a) completamente } \\
\text { brancos; b mulatos } \\
\text { claros; c) mulatos; d) } \\
\text { negros, mas com alguma } \\
\text { mistura com brancos; } \\
\text { e) negros; f) indígenas } \\
\text { ou com alguma } \\
\text { descendência indígena }\end{array}$ \\
\hline $\begin{array}{c}\text { Estudo } \\
\text { Comparativo dos } \\
\text { Interesses dos } \\
\text { Adolescentes de } \\
\text { Diferentes Meios } \\
\text { Sociais (1953) }\end{array}$ & $\begin{array}{l}\text { Arquivos } \\
\text { Brasileiros de } \\
\text { Psicotécnica }\end{array}$ & $\begin{array}{l}\text { Verificar se os } \\
\text { interesses de jovens } \\
\text { em idades escolar } \\
\text { variavam de forma } \\
\text { significativa com } \\
\text { o seu meio social } \\
\text { e econômico, } \\
\text { para investigar se } \\
\text { características dos } \\
\text { testes de inteligência } \\
\text { podem influenciar } \\
\text { os resultados obtidos } \\
\text { por crianças de } \\
\text { diferentes meios } \\
\text { socioeconômicos e } \\
\text { grupos étnico-raciais. }\end{array}$ & $\begin{array}{l}\text { Questionário Social e } \\
\text { Catálogo de Livros de } \\
\text { F. Baumgarten Tramer, } \\
\text { modificado por Mira y } \\
\text { López }\end{array}$ & $\begin{array}{l}251 \text { alunos das } \\
\text { quatro séries } \\
\text { do ginásio, com } \\
\text { idades entre } \\
11 \text { e } 14 \text { anos. } \\
\text { Classificados } \\
\text { quanto ao seu } \\
\text { meio social (com } \\
\text { base na profissão } \\
\text { dos pais) e ao seu } \\
\text { meio econômico } \\
\text { (com base nas } \\
\text { posses materiais } \\
\text { da família). }\end{array}$ & 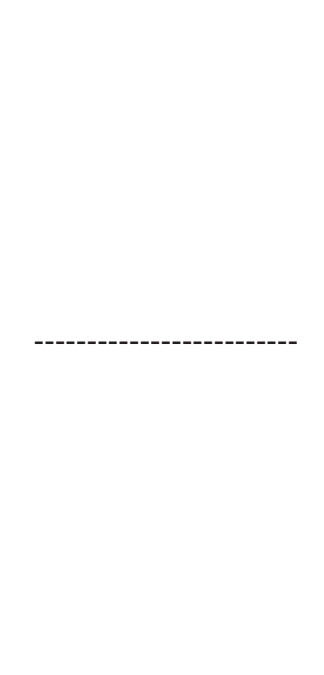 \\
\hline $\begin{array}{l}\text { Psicologia } \\
\text { Diferencial } \\
\quad(1953)\end{array}$ & $\begin{array}{l}\text { Klineberg, } \\
\text { O. et al., A } \\
\text { Psicologia } \\
\text { Moderna }\end{array}$ & $\begin{array}{l}\text { Analisar a natureza } \\
\text { e a manifestação } \\
\text { das diferenças } \\
\text { individuais e entre } \\
\text { grupos encontradas } \\
\text { em estudos } \\
\text { comparativos sobre } \\
\text { as características } \\
\text { físicas e psíquicas; de } \\
\text { inteligência, de idade, } \\
\text { entre a população } \\
\text { urbana e rural, entre } \\
\text { os sexos e entre as } \\
\text { raças. }\end{array}$ & Análise Bibliográfica & $\begin{array}{l}\text { Participantes de } \\
\text { diversos estudos } \\
\text { comparativos }\end{array}$ & $\begin{array}{l}\text { As classificações raciais, } \\
\text { em geral, utilizavam } \\
\text { a heteroclassificação } \\
\text { e critérios físicos (cor } \\
\text { da pele, dos olhos e } \\
\text { dos cabelos; forma dos } \\
\text { cabelos; dimensões do } \\
\text { corpo; índice cefálico; } \\
\text { medidas faciais; grupos } \\
\text { sanguíneos. }\end{array}$ \\
\hline
\end{tabular}


Quadro 2

Organização da produção de Aniela Ginsberg sobre relações étnico-raciais e interculturais (Continuação).

\begin{tabular}{|c|c|c|c|c|c|}
\hline $\begin{array}{l}\text { Título e Ano } \\
\text { de Publicação }\end{array}$ & Fonte & Objetivo(s) de pesquisa & Método(s) Utilizado(s) & $\begin{array}{l}\text { População Sob } \\
\text { Estudo }\end{array}$ & $\begin{array}{c}\text { Vocabulário } \\
\text { utilizado para se } \\
\text { referir aos grupo } \\
\text { étnico-raciais }\end{array}$ \\
\hline
\end{tabular}

\section{Pesquisas} sobre as

Atitudes de um Grupo de Escolares de São Paulo em Relação com as Crianças de Cor (1995)

\section{Bastide, R. \&} Fernandes, F.

Relações raciais entre negros e brancos em São

Paulo.

\begin{abstract}
Analisar a) se no meio escolar existia preconceito de raça, quais suas formas e graus; b) qual a atitude de crianças de idade escolar em relação aos colegas brancos e de cor; c) se existiam atitudes hostis devido às diferenças raciais; d) se as crianças podiam se identificar com seus respectivos grupos; e) se havia modificações dessas atitudes com relação à idade, ao sexo, ao meio social e à cor das crianças.
\end{abstract}

Jogo lúdico e
Interpretação de
Quadros Ilustrativos

provenientes de três socioeconômicos: escola primária $\mathrm{A}$ (filhos de famílias pobres, operárias e artesãs, de um bairro com grande número de população negra); escola primária $\mathrm{B}$ (filhos de famílias operárias com nível econômico um pouco mais elevado de um bairro com a maioria da população branca) e escola primária $\mathrm{C}$ (filhos de pais ricos de um dos melhores bairros residenciais, onde existiam apenas mulatos muito claros).
As crianças estudadas foram classificadas em três grupos segundo a cor: brancos $(80,3 \%)$, mulatos $(13,4 \%)$ e negros $(6,3 \%)$.

\section{3 jovens} universitários do sexo masculino, com idade entre 18 e 28 anos, de três grupos diferenças sociais e culturais influenciavam as atitudes e a personalidade de jovens de três países muito diferentes.
Teste de Borrões de Tinta de W. Holtzman étnicos: brasileiros, japoneses e poloneses. Os sujeitos foram divididos em quatro grupos com base no nível educacional
Os jovens foram divididos em três grupos étnicoraciais: brasileiros (com os quatro avós brasileiros), japoneses e poloneses.
Interamericano
de Psicologia
Culturais

(1973)
Um Estudo

Pertencentes a

rês Diferentes$$
(1973)
$$

\begin{tabular}{ccc}
\hline $\begin{array}{c}\text { Um estudo } \\
\text { comparativo } \\
\text { de aspirações } \\
\text { culturais e }\end{array}$ & $\begin{array}{c}\text { Revista de } \\
\text { Estabelecer a influência } \\
\text { de fatores socioculturais } \\
\text { profissionais }\end{array}$ & $\begin{array}{c}\text { Psicologia } \\
\text { sobre o nível e a direção } \\
\text { das aspirações dos }\end{array}$ \\
em estudantes & Normal e & estudantes universitários \\
brasileiros & Patológica & e sobre certos aspectos de \\
de diferentes & & sua personalidade. \\
origens étnicas & &
\end{tabular}
do pai. 